\title{
NIÑOS Y NIÑAS HACIENDO MEMORIAS DE SU POBLACIÓN: \\ INFANCIA, MEMORIAS LOCALES Y TERRITORIO
}

René Serey Madrazo - Universidad Academia de Humanismo Cristiano

René Serey Madrazo

Psicólogo Universidad Diego Portales Magíster en Psicología mención Psicología Comunitaria Universidad de Chile Docente escuela de Psicología Universidad Academia de Humanismo Cristiano

\section{Agradecimientos:}

Este artículo de investigación científica y tecnológica (Otras ciencias sociales: área interdisciplinaria), se basa en la tesis de magíster de la Universidad de Chile «Niños y niñas haciendo memorias de su territorio: Construcción de Memorias locales en la población Lo Hermida.». Financiado por el Proyecto FONDECYT N 1161026 "Memorias locales y transmisión intergeneracional: estudio de caso de un "barrio crítico" en Santiago de Chile".

\section{Correspondencia:}

René Serey

rsereym@yahoo.es 


\title{
Resumen
}

La siguiente investigación se enmarca dentro de los estudios de memorias locales, específicamente se centra en las construcciones locales de memorias de niños y niñas en una población emblemática de Santiago, la población Lo Hermida. Para esto, se realizaron cinco sesiones de trabajo, en donde los niños y las niñas produjeron de manera participativa y creativa diversas técnicas a través de las cuales contaron historias de su población. Para comprender lo anterior, se utilizó el análisis narrativo de tipo estructural y se dio cuenta de cómo los niños y niñas utilizan las huellas en el territorio, los personajes y lugares del espacio público de su población que remiten al pasado de la misma. Así como también de recursos externos proporcionados por los medios de comunicación para construir distintos pasados capaces de explicar el presente de su cotidiano y de alguna manera articular memorias que buscan la unidad y la convivencia.

Palabras clave: infancia; memoria social, memorias locales, territorio.

\begin{abstract}
The following research is framed within the studies of local memories, specifically on the construction processes of local memories of children that live in Lo Hermida, an emblematic slum located in Santiago. Throughout the completion of five sessions, children engaged creatively and actively in performing diverse techniques that prompted them to tell stories about their neighborhood. In order to comprehend the above, a structural type of narrative analysis was employed and sought to give account of the manner in which children utilize territorial traces, characters and public spaces that in turn recall their past. Further aspects were also included such as external resources provided by mass media to construct different narratives of the past that are capable of explaining the current daily life and somehow articulate memories that search for the unity and coexistence of the community.
\end{abstract}

Keywords: chilhood; social memories; local memories; territory 


\section{Introducción}

Desde la década de los años setenta las Ciencias Sociales han abocado parte de su investigación a temáticas de memoria, enfocadas principalmente a sociedades enfrentadas a violencias y represiones políticas en dictaduras. De esta manera, parte de los estudios de las memorias se han situado en los contextos de los llamados países del Cono Sur, producto precisamente, de sus pasados de gobiernos autoritarios, donde las violaciones a los Derechos Humanos (DDHH) formaron parte de la cotidianidad (Reyes, Jeanneret \& Cruz, 2016). Sin embargo, en la actualidad es posible identificar estudios sobre las memorias en distintos ámbitos, tales como la exploración a nivel local, así como la atención a una mayor diversidad de actores, pero que, sin embargo, siguen siendo estudios incipientes en su producción (Reyes et al., 2016). De esta forma, es posible reconocer una tenue diversificación y apertura de los estudios de la memoria superando el nivel de análisis entorno a lo nacional y a la víctima como único actor, centrando la investigación en contextos locales en donde surge la necesidad de mirar lo local pues este nivel permite identificar las configuraciones más específicas y densas con las que se confrontan las memorias nacionales al momento de articular sus relatos sobre el pasado.

Esta articulación se engrana en un escenario socio-político comandado por una reorganización del modelo neoliberal, el cual busca instalar sus propias constelaciones de sentidos en todos los niveles de la sociedad. Caracterizándose por no entender al poder político central y social como el centro de operaciones desde donde reproducir sus formas de funcionamiento, sino más bien, irradiando su lógica de mercado también a esferas como la familia, la natalidad, la delincuencia, etc., reorganizando no solo lo económico, social y político sino también los sistemas de valores de las sociedades (Calveiro, 2006). 
Las memorias no son ajenas a esta reorganización del neoliberalismo, sino que más bien operan como puente de procesos históricos y sociales que "permanentemente inauguran lo novedoso a la vez que establecen nexos y continuidades con lo ya vivido" (Calveiro, 2006, p.377), produciendo una tensión con el corte radical que suelen instalar estas constelaciones de sentido propios del modelo neoliberal actual. De esta manera, las memorias permitirán recordar aquello que se borra del pasado o bien se confina en él precisamente por sus incómodas resonancias con el presente (Calveiro, 2006). En este sentido, habrá que entender que no existen las memorias neutrales sino más bien lo que existe son formas diferentes de articular lo vivido con el presente. Formas que pueden ser a favor de reproducir el statu quo imperante en una sociedad, como a generar resistencias al mismo.

Dicho todo esto, será posible sostener entonces lo local como nivel de observación en tanto permitirá comprender, por un lado, las constelaciones de sentidos que los grupos y comunidades ancladas a un territorio le dan a sus propias prácticas y en particular le dan a su presente y por consecuencia, a su pasado. Y por otro, permitirá dar cuenta de las formas y los movimientos que se dan en el actual contexto de expansión del neoliberalismo, el cual acarrea una constelación de sentidos y temporalidades que entrarán en disputa y consenso con lo local. Cabe preguntarse entonces no sólo por el nivel de lo local, sino también, como se presentó en un comienzo, por los actores sociales que están implicados en esas redes, quienes, por lo demás, según sus posibilidades de participación y de reconocimiento social dentro de las tramas de la memoria, será de quienes dependerá el cómo, para qué y para quién o quiénes se hacen las memorias. En este sentido existen actores sociales en las tramas de producción de las memorias que carecen de lugares legitimados de participación en la construcción del pasado. Específicamente serán los niños y niñas, entre otros actores, quienes históricamente se les ha situado en un lugar de pasividad y contemplación, no 
escapando de esto los estudios de las memorias que han evidenciado un lugar de sujeción pasiva a las transmisiones adultas del pasado (Álvarez y Hedrera, 2015). Dicho esto, es que por lo tanto el objetivo de esta investigación es identificar cómo construyen memorias locales sobre su población los niños y niñas de Lo Hermida.

\section{Material y Método}

Este trabajo se realizó en una reconocida población emblemática del sector oriente de Santiago, la población Lo Hermida. Principalmente por su trayectoria histórica marcada por las movilizaciones de pobladores y la permanente rearticulación territorial, consecuencia del esfuerzo colectivo que significaron las tomas de terreno que dieron origen a la población en los años 70 . Además de volverse un territorio de constante conflicto con el Estado ya fuera en época de la Unidad Popular como de dictadura cívico-militar, siendo esta última la que forzó a Lo Hermida, a constituirse como lugar de resistencia de otra forma de vida a la que la dictadura trataba de imponer. Lo Hermida es entonces, un territorio específico dentro de la Región Metropolitana, con una historia y una identidad local en conflicto permanente con las políticas de Estado y del mercado (Aninat, 2016), reaccionando constantemente a la coyuntura social y política de las últimas décadas en la historia de Chile.

Puntualmente se trabajó en las instalaciones de un jardín infantil comunitario del sector, al cual asistieron previa invitación, niños y niñas de entre 8 a 13 años quiénes participaron de 5 sesiones impartidos una vez por semana entre los meses de octubre y noviembre del año 2017. Cada sesión tenía una duración de una hora y treinta minutos. Dividiéndose en un espacio de taller y otro de plenaria. Desarrollando en el primero un trabajo creativo en torno a la construcción creativa de una historia cuyo tema y metodología eran escogidos por el colectivo al comenzar la sesión. En esta primera instancia se presentaban a elección tres maletas, cada una con el nombre 
del tipo de historias a construir. En la primera decía "Historias de lugares de Lo Hermida", en la segunda "Historias de personajes de Lo Hermida" y en la tercera "Historias de momentos importantes en Lo Hermida". Elegida la maleta, se les presentaba mediante ilustraciones representativas las distintas metodologías. Se les explicó de qué trataba cada una de ellas y ellos decidían.

La segunda instancia antes mencionada, la plenaria, duraba 45 minutos y se realizó en la segunda y última parte de cada sesión. En ella se disponía un espacio circular ideado para conversar, para usar las palabras y explicar las ideas construidas además de compartir sensaciones y sentimientos sobre la jornada, así como también ideas e impresiones que permitieran ir haciendo las sesiones más gratas para todo el grupo. Todo esto con la finalidad de generar un espacio de participación y creatividad flexible, buscando en todo momento facilitar el protagonismo de niños y niñas, con tal que el espacio y las actividades fueran apropiadas por ellos y pudieran darle el uso que precisaran. Para llevar a cabo lo anterior, se utilizó la metodología cualitativa de tipo Participativas en Investigación Social Comunitaria, desde ahora ISC (Canales, 2006).

A modo de métodos, técnicas y formas de hacer registro, para esta investigación se escogieron, por una parte, el Método Descriptivo y por otra, se utilizó el Método de análisis narrativo el cual permitió analizar las prácticas narrativas tanto de los propios sujetos, como de los grupos y/o colectividades que se narran así mismo. Poniendo el énfasis en las formas de “tergiversar" el lugar que los propios sujetos habitan en las narraciones, resaltando las posibilidades de agencia que surgen en estos procesos y que demuestran que los discursos dominantes no solo se entrelazan con resistencias, sino que son apropiados por los propios sujetos y resignificados por estos mismos. En este sentido, los análisis narrativos se centraron principalmente en identificar en el relato las formas en cómo se expresa la propia producción de 
uno(s) mismo(s) en relación a las posibilidades que ofrece la experiencia y los discursos que se ponen en juego para significarla. Aquí no interesó tanto específicamente las formas de resistencia sino más bien, el cómo se construye una narrativa que define la propia vida. El análisis narrativo entonces, se centró en analizar el relato, el cual es básico dentro toda historia que se construye (Capella, 2011).

\section{Tabla 1:}

Estructura de cada sesión

\section{Sesiones}

\section{Técnicas}

\begin{tabular}{cc}
\hline Presentación & $\begin{array}{c}\text { Encuadre } \\
\text { Nombres y motivación } \\
\text { Instrucciones }\end{array}$ \\
\hline $\begin{array}{c}\text { Mistorias de lugares en } \\
\text { Lo Hermida" }\end{array}$ & $\begin{array}{c}\text { Mapa Parlante } \\
\text { Video Ruta } \\
\text { Foto-palabra }\end{array}$ \\
\hline "Historias de personas en \\
Lo Hermida" & Rol-playing \\
\hline Foto-palabra \\
\hline Lo Hermida" & Video Forum \\
Dramatización \\
\hline Plenaria & Rotafolios plásticos \\
\hline & Síntesis de sensaciones \\
& Aclaración de historias \\
\hline
\end{tabular}




\section{Resultados}

Tabla 2:

Resultados por sesión

\begin{tabular}{|c|c|c|c|}
\hline Sesión & Maleta escogida & Técnica escogida & $\begin{array}{c}\text { Historias contadas en esta } \\
\text { sesión (nombre de creador/a): }\end{array}$ \\
\hline $\begin{array}{l}\text { Sesión I } \\
20.10 .2017\end{array}$ & $\begin{array}{l}\text { "Historia de personas } \\
\text { en Lo Hermida" }\end{array}$ & Foto-palabras & $\begin{array}{l}\text { La papa despertador }(\mathrm{F}) \\
\text { La Rutina }(\mathrm{J}) \\
\text { En busca de mi sueño ideal. (A.P) } \\
\text { El corazón del fin }(\mathrm{A}) \\
\text { Yo y mis gatos }(\mathrm{Ll})\end{array}$ \\
\hline $\begin{array}{l}\text { Sesión II } \\
01.11 .2017\end{array}$ & $\begin{array}{l}\text { "Historia de personas } \\
\text { en Lo Hermida" }\end{array}$ & Rol playing & $\begin{array}{l}\text { Piratas (L1, M, Ly G) } \\
\text { La pelea entre empresarios y } \\
\text { diablos (Ll, M, L y G) } \\
\text { El empresario y el vagabundo (F } \\
\text { y J) }\end{array}$ \\
\hline $\begin{array}{l}\text { Sesión III } \\
04.11 .2017\end{array}$ & $\begin{array}{l}\text { "Historia de lugares en } \\
\text { Lo Hermida" }\end{array}$ & Mapa parlante & $\begin{array}{l}\text { El breakdance }(\mathrm{F} \text { y B) } \\
\text { El mural (A.P. y S) } \\
\text { El restaurante que se incendió } \\
\text { (A.P y S) } \\
\text { La plaza de los mapuche (Ll) }\end{array}$ \\
\hline $\begin{array}{l}\text { Sesión IV } \\
08.11 .2017\end{array}$ & $\begin{array}{l}\text { "Historia de lugares en } \\
\text { Lo Hermida" }\end{array}$ & Video-ruta & $\begin{array}{l}\text { Lugares que hablan (F, V, J y V) } \\
\text { Puño rojo } 1 \text { (A.P y A) } \\
\text { Puño rojo } 2 \text { (M, L, B, A y Ll) }\end{array}$ \\
\hline $\begin{array}{l}\text { Sesión V } \\
11.11 .2017\end{array}$ & $\begin{array}{l}\text { "Historia de momentos } \\
\text { importantes de Lo } \\
\text { Hermida" }\end{array}$ & $\begin{array}{l}\text { Dramatización } \\
\text { con títeres }\end{array}$ & $\begin{array}{l}\text { Grupo títeres 1: La fundación de } \\
\text { Lo Hermida (A, B y S) } \\
\text { Grupo títeres } 2: \text { La historia de la } \\
\text { papa despertador (J, F. V y V) }\end{array}$ \\
\hline
\end{tabular}

En las cinco sesiones llevadas a cabo surgieron diversas formas de producción entorno al pasado del territorio. Cada una de ellas guardó relación con distintas líneas de análisis posible. Por una parte, la relación con el pasado fue diversa abriendo distintas posibilidades temporales con este, es decir, distintos pasados enmarcados en contextos más o menos próximos al territorio entre otros elementos. El uso de personajes también fue variando según del tipo de relación con el pasado que se usaba, así como también la utilización de distintas fuentes de imágenes, significados y 
símbolos de las que las historias de iban nutriendo. A partir de lo anterior, es que se organizaron tres categorías analíticas para explicar los resultados que se detallan a continuación:

\section{La multiplicidad de pasados recientes en el relato de niños y niñas:}

Al analizar las construcciones de los niños y niñas en las distintas sesiones, es posible interpretar el surgimiento de diversos pasados relacionados con los distintos usos conferidos por estos sujetos. En todos los casos, el pasado referenciado es un pasado reciente, vale decir, de breve existencia y data. Es un pasado cercano y próximo en el tiempo, por momentos vecino de un tiempo presente. En el caso de esta investigación es plausible diferenciar en tres categorías este pasado reciente utilizado por los niños y niñas y hablar de un pasado que es inmediato, otro que es cercano y uno que es más distante con características de un relato fundacional respecto del presente expuesto. Cada uno de estos pasados recientes son utilizados en las distintas sesiones al momento de contar las diferentes historias.

Respecto al pasado inmediato, se identifica un protagonismo de un personaje principal en la historia, el cual suele ser una caricatura del mismo niño/a que creó la historia. Además de ser un relato sin una trama muy clara y ser difícil de distinguir temporalmente, vale decir, el pasado se confunde con el presente pareciendo más un relato continuo del día a día de cada niño/a.

En el caso de F en la sesión I, se transmite una historia que es pasada al mismo tiempo que es actual.

\section{F, Sesión I}

René: ¿Cuándo fue? Si tuvieras que decirme un momento....

F: Fue como a ayer. Ayer fue.

René: Ya y ¿en qué momento del día?

F: Cuando estaba despertando, no podía despertar. 
René: ¿y esto te pasa solo una vez?

F: Me pasa siempre. ¡Por eso la hice!

En ambos casos ellos refieren la existencia de una rutina diaria en donde se inscribe esta historia, que, para efectos de la actividad, parece haberse extirpado de este presente rutinario y haberse vuelto una fotografía instalada en un pasado que es reciente, porque para contarse tiene que tomar distancia de lo actual.

Figura 1:

Sesión I, autora J, La rutina

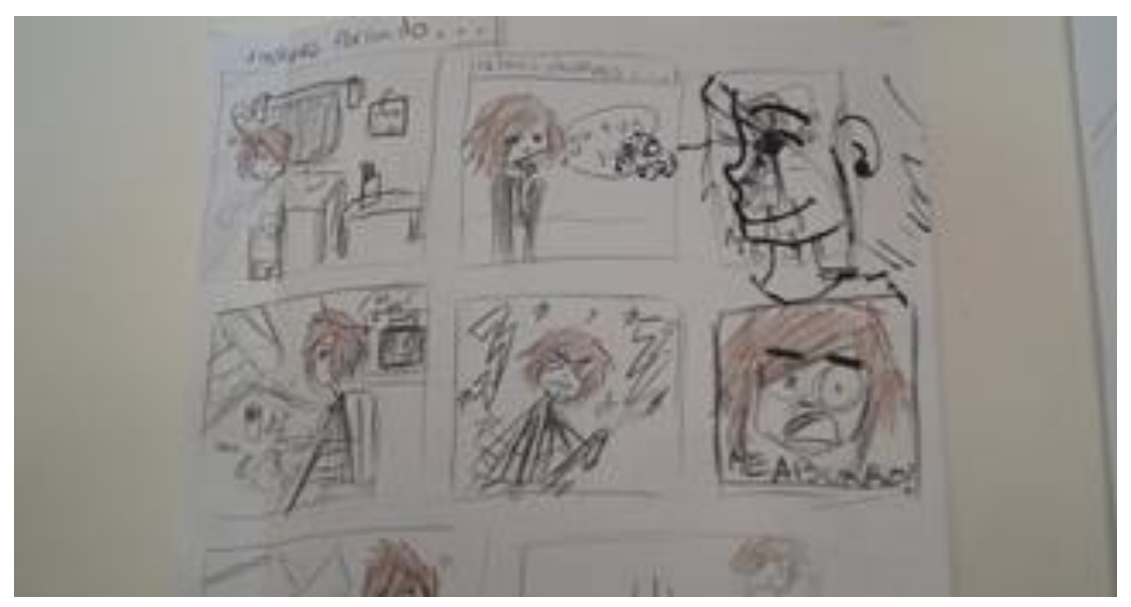

El pasado cercano aparece en una menor frecuencia y se caracteriza por poseer una clara trama central dejando incluso relegados a un segundo plano a los personajes principales que no siempre son representaciones de los mismos niños y niñas. Este pasado es situado a lo máximo como un año de distancia con el presente.

Por último, aparece el pasado fundacional. Este pasado se caracteriza por ser el más distante respecto al presente, situándose entre 4 a 5 años atrás en algunos casos y en otros no poseer fecha. Es un pasado cuya trama tiende a narrar los orígenes de personajes, situaciones o lugares de la población, utilizando personajes primordialmente ficticios y fantasiosos. 


\section{Marcos colectivos de las memorias de niños y niñas}

Se han presentado distintos elementos que sirven de análisis para entender los diversos marcos desde donde los niños y niñas de Lo Hermida se sitúan para recordar. Sin lugar a dudas el marco de lo local traducido a los lugares que frecuentan con cierta cotidianidad los niños y niñas, sea en la esfera doméstica como en lo público, parece un referente básico y fundamental desde donde situar y nutrir a las historias aquí expuestas. Es en la mayoría de los casos que estos ámbitos delimitan el contexto y la escenografía de las narraciones, incorporando y transformando ambientes, personajes y relaciones según sea el interés colectivo de esa historia. Se ha visto que en la medida que el relato genera una mayor distancia temporal con el presente el marco se flexibiliza y permite entrar a la fantasía como fuente auxiliadora, no obstante, la misma fantasía y ficción retoman y transforman elementos de lo local. Distinto es el relato que se desarrolla con mayor cercanía en el tiempo, donde lo local aparece más de manera más concreta y reconocible, tanto así que parece un anecdotario del territorio y su habitar cotidiano.

Así, por ejemplo, en una de las tantas historias se incorporan lugares comunes de Lo Hermida, tales como los bares y restaurantes tan habituales de la población. Se trata aquí de un espacio de encuentro hecho para gozar un buen momento, pero que sin embargo, es destruido por un incendio. Aquí el pasado es reciente y cercano, es una historia de hace un par de años, el lugar es el protagonista de la narración, dejando a los habitantes de Lo Hermida que lo transitaban en un segundo plano. No obstante, surge en esta historia un nuevo y reiterado final, el abandono de los vecinos sobre este lugar, el cual proporcionaba "comida rica" pero que al ser destruido por el fuego terminaría siendo abandonado por los vecinos pese, a como cuenta $\mathrm{S}$, a seguir funcionando en la actualidad. 


\section{S y A.P. Sesión III}

S: Entonces pasan por aquí, pasan por el, la, el mural destruido y se van a su trabajo. René: Ya bacán.

Y por último, ¿cuál es la experiencia de ustedes en este lugar?

S: Que, no porque haya habido una explosión y se les hayan quemado las pizzas tienen que, porque ese lugar siguió en pie entonces que no tendrían que haber dejado de ir.

Figura 2:

Sesión III, autores AP y S, La historia del mural

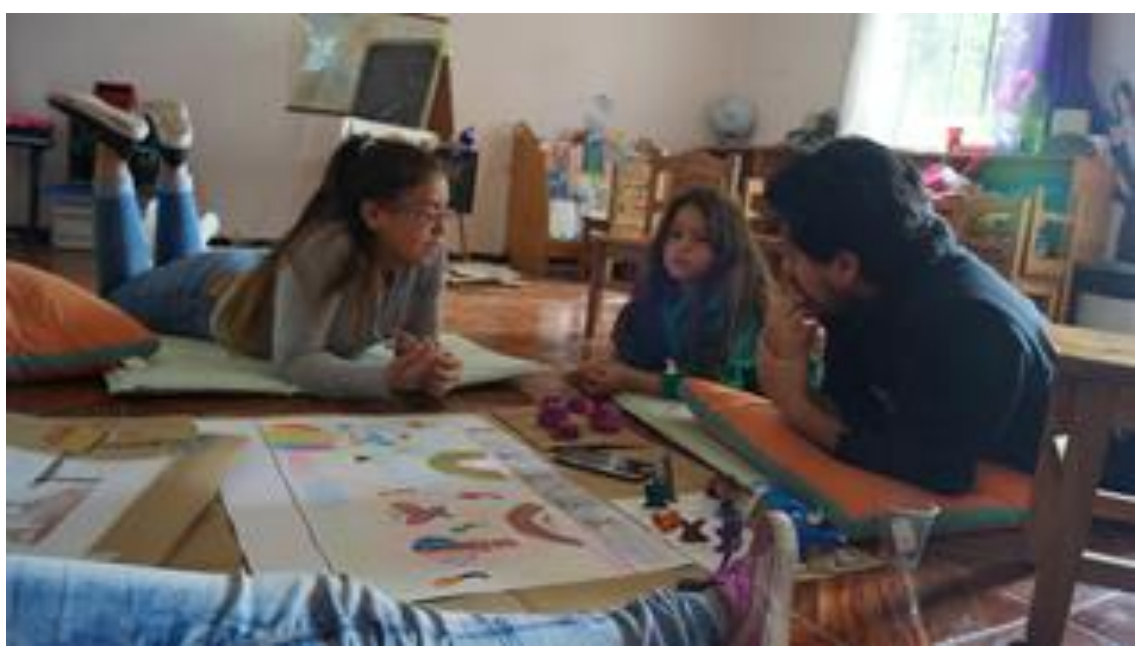

Se presentan aquí elementos que atraviesan estos marcos más tradicionales y se incorporan dentro de los relatos, ya sea para auxiliarlos en pasados más lejanos como para dinamizar la narración de lo más concreto y cercano. Por otro lado, los medios de comunicación hacen su aparición con una inusitada relevancia en las narraciones sobre Lo Hermida. Al mismo tiempo, el espacio de lo público en Lo Hermida, presenta matices y significaciones particulares que también contribuyen a situar el pasado de manera diversa. Aquí se habla de pasajes, de calles, de barrio, de plazas, de vecinos, de locales de comida, de botillerías, etc. Es decir, de un sin fin de elementos 
idiosincráticos con los cuales se construye el territorio y lo que atañe a este trabajo, las memorias de niños y niñas sobre este.

Una de las narraciones, por ejemplo, se trata sobre el muro que Donald Trump (presidente actual de los Estados Unidos) pondría en la frontera con México. En esta sesión, se utiliza un muro que está detrás del jardín infantil donde se realizan las sesiones de esta investigación. En esta historia, los niños y niñas se trasladan desde Lo Hermida hasta Estados Unidos, no obstante, se mantiene una relación de los personajes con lo latinoamericano. Al mismo tiempo se perfilan personajes locales, referidos en otras sesiones, como vagabundos y borrachos en las plazas, quienes, en esta ocasión, son usados como los interlocutores del conflicto que presenta el muro de Donald Trump en ese lugar. Al mismo tiempo que ese muro es el lugar central, el modo de abordar la actividad de esta sesión, guarda directa relación con un programa de reportajes de un canal de televisión nacional "Lugares que Hablan”.

\section{Muro de Trump, Sesión IV}

J: Bueno y como vemos aquí los niños de Latinoamérica y sudamérica que viven en México se les va a prohibir su sueño de toda la vida de ir a Estados Unidos, que pena...

[F golpea el muro a patadas]

J: ¡Señor por favor! Tení que ser respetuoso.

F: Ahora terminan "lugares que hablan”. ¡Y aquí termina!

Todos: ¡Lugares que hablan! [...]

$\mathrm{J}$ : Ahora vamos a mirar el muro, se ve que es un poco rústico, se ve que aún está en construcción el muro de Donald Trump para que los mexicanos... [Niños lanzan botella al muro] 
De esta manera, la cotidianidad de la población está presente en los relatos y son los quiebres producidos por momentos y personajes ficcionados los elementos o situaciones que la alteran momentáneamente. Es a través de la interacción con el espacio local y global que se van produciendo identidades particulares de una comunidad que recuerda. Se le encuentra un sentido al lugar de las memorias desde uno mismo y de los otros. Estas interacciones entre lo local y lo global constriñen y/o contradicen (tensionan) los normales usos del espacio, por cuanto colaboran a generar nuevos elementos desde donde pensar la participación del/a niño/a, el mismo espacio y la memoria (Álvarez, y Heredia, 2015). Será precisamente la amplia cantidad de significaciones y objetos que ofrecen estos marcos, desde donde se podrán elaborar interpretaciones del pasado y del presente, aportando a la diversificación de usos y sentidos en la relación significativa que los niños hacen con el territorio. Por cuanto, ponen en discurso ámbitos que los aquejan desde sus discursos particulares.

Por último, cabe mencionar a los medios de comunicación como un marco específico y a la base de muchas prácticas, significados y conceptos utilizados para articular los relatos y presentarlos. En la mayoría de las sesiones aquí presentadas es plausible encontrar referencias a noticieros como en algunos casos que se habla de la historia del pueblo mapuche o de sus formas de resistencia. Posicionando estos eventos en un tono confrontacional o de un cierto reproche o denuncia.

\section{El conflicto como motor de las tramas del pasado en el territorio}

La mayoría de las historias que se han ido retratando en este trabajo, ya han mostrado distintos elementos de singularidad. Se ha hablado de que su construcción utiliza elementos tanto locales como globales, que son entremezclados como un todo narrativo que configura un sentido de realidad cotidiana al territorio. Para esto, se ha dicho que los marcos más cercanos como lo 
doméstico y lo público han resultado ser las bases desde donde enmarcar la experiencia y situar los distintos pasados que se quieran contar, generando en la narración una distancia mayor entre pasado y presente en función de lo que se conoce y de lo que se quiera recordar. No obstante lo anterior, existe un elemento recurrente en la mayoría de estas historias que es el conflicto, el cual aparece en las historias como una suerte de motor de sus narraciones, por cuanto las pequeñas tramas llegan a sus puntos más álgidos cuando se produce una oposición de fuerzas entre sus personajes. No obstante, también aparece este conflicto como tema abordado en algunas historias, y no necesariamente como confrontación como pasaremos a ilustrar y revisar a continuación.

En la sesión II por ejemplo, es posible identificar ciertos lugares que se sitúan en espacios comunes del territorio tales como completerías, bares y botillerías, además de usar personajes reconocibles en lo local, tales como vagabundos, borrachos, traficantes y otros quizás desde una categoría más mediática como los empresarios. Lo que interesa a este punto es que en los espacios usados para estas narraciones, se concentran conflictos entre, principalmente adultos, ya sean por sus peleas a golpes, robos de un personaje a otro, o una confrontación entre sujetos desiguales. Lugares que son usados para mostrar conflicto entre personajes que son fantásticos, ficcionados y por sobre todo adultos. Por el contrario, en el opuesto es situada la figura del empresario como un sujeto portador de "un algo" que el personaje más local no posee (un maletín en una de las historias y una enseñanza en la otra).

De esta manera es posible sostener que en varias de las historias de personajes tienen como factor común el antes mencionado conflicto entre fuerzas opuestas como trama central de sus relatos, y que son conflictos posibles de pesquizar en la actualidad tanto de Lo Hermida como en la realidad más mediática (robos, tráfico e idealización de sujeto empresario). Esto, como otro ejemplo más de que los niños y las niñas para construir el pasado van incorporando una amplia 
variedad de fuentes, siendo, sin embargo, para el caso de esta sesión, los locales de bebestibles y de comida los más utilizados para mostrar el conflicto. El conflicto entonces, de alguna manera, es una forma de vincularse con la cotidianidad de Lo Hermida, a través de ciertos lugares y no otros, la mayoría partes del espacio público, principalmente de la calle.

En relación una historia de la sesión II, la historia del "puño rojo", surgen dos narraciones que tienen como elemento común el conflicto, pero esta vez, uno que es violento y sangriento y ya no opone dos fuerzas, sino más bien hace aparecer la violencia de un lado sobre otro que no resiste. Lo anterior representa una enseñanza, una suerte de moraleja para el sujeto que transite en donde esta ubicada esa estatua, puesto que desde él hay que aprender y, por lo mismo, se debe tener un recuerdo vivo, para de esta manera hacerlo habitable, sin ese tipo de conflictos que en este caso, costó una vida.

\section{Historia del puño rojo 2, Sesión IV}

[B habla sobre la representación teatral que acaba de hacer su grupo para mostrar la historia que quieren contar de ese lugar]

B: Ahí me habían cortado con...me comenzaba a salir sangre [en el brazo]...

\section{Video Puño rojo 3}

R: Y en esta plaza dejaron esto [apuntando al puño rojo] ¿por qué?

M: Porque acá fue lo que hicieron.

A: porque el asesinato

Figura 3:

Sesión IV, El puño rojo 


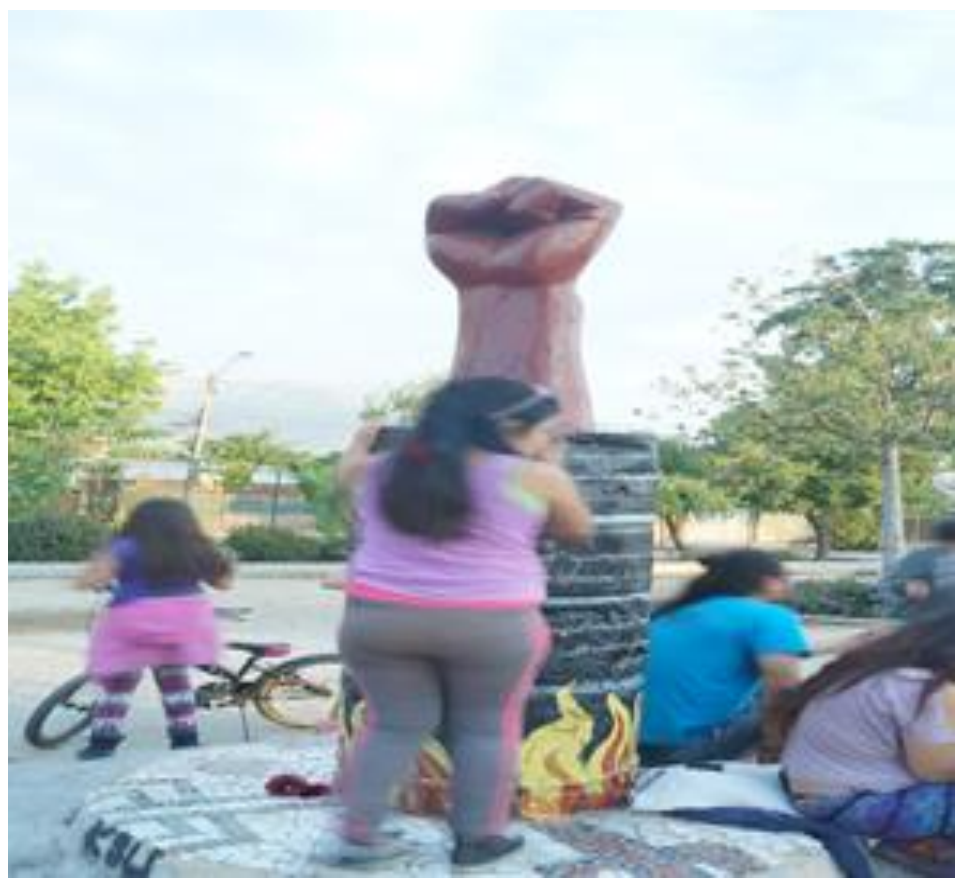

Según Raposo (2013), el hecho de que una comunidad esté anclada a un territorio posibilita la producción de memorias sobre este, por cuanto se construyen narrativas que permitan dar sentido a lo que ahí ocurrió. Esta operación de sentido estaría dada para la autora por la necesidad de continuidad en el relato del territorio, en particular, si ese espacio se encuentra atravesado por acontecimientos violentos. En ese escenario las comunidades organizarán el tiempo y el espacio, centrando su mirada siempre en el presente. De esta manera, los niños y niñas que participaron de este trabajo, han expuesto una recurrente necesidad de poner en narración una serie de conflictos en el territorio. Señalando y referenciando marcas y huellas en este (el puño en rojo, el muro, etc.) que significan posibles acontecimientos de algún tipo de violencia, los cuales son agenciados y procesados por los niños y niñas, en tanto ofrecen temporalidades y tramas que explican y dan sentido al conflicto instalado en los lugares, además de señalar posiciones respecto a estos “acontecimientos" mostrando posibles salidas o soluciones a ellos, dando cuenta de una capacidad de tomar las marcas de su territorio y leerlas en función de un presente, otorgándoles una trama de 
sentido que permita en todos los casos, superar esos conflictos tanto colectiva como individualmente. De allí que la memoria para este caso, aparezca como un elemento de resistencia al lugar tradicional que se le da a la infancia siendo esta última capaz de reconstruir un pasado social, político y comunitario que se hace necesario para el presente (Chacón, 2017), en la perspectiva de los niños y niñas en tanto actores sociales y miembros de una comunidad.

Por otra parte, es posible pensar la calle como un espacio con ciertas especificidades respecto al territorio. Según Giannini (2004) la calle y los conflictos que en ella se presentan, se vuelven rutina, vale decir, se relatan en un presente continuo que se manifiesta libremente en este espacio y desde donde habrá que enfrentar el futuro sin más remedio. El conflicto sería entonces una marca "fijada con fuego" en los niños y niñas de Lo Hermida, quienes parecen entender el pasado, el presente y el futuro, en lo que parece una relación "inmanente" con la pelea, la lucha, la violencia y la confrontación (Giannini, 2004). No obstante, la calle ofrece también la posibilidad de "lo abierto", en el sentido de "tomar otro camino", Giannini dirá de "tomar la amenaza del desvío, del extravío; la posibilidad de que en virtud de un reencuentro fortuito ocurra un cambio radical de la ruta; o en virtud de un reencuentro, una aventura con el pasado.'(2004, p.44). De esta manera, la utilización del conflicto en las tramas de las narraciones que usan la calle y el parque para contarse, pueden presentar el presente continuo otorgado por los grupos sociales y la comunidad de los niños y niñas, no obstante, la utilización de personajes, elementos y situaciones locales como mendigos, borrachos y personajes ficcionados, quizás lo que buscan es realzar figuras actuales pero "invisibles" socialmente, y desde ellos "tomar otro camino" para enfrentar el “conflicto continuo" posiblemente enmarcado en las memorias y en el presente de su población. 


\section{Conclusiones}

Es posible sostener que la mirada de los niños y niñas tiene particularidades en relación al lugar social que ocupa la infancia en la producción de las memorias sobre un territorio. En este escenario se ha podido identificar una producción activa y agenciada del pasado del territorio por parte de estos sujetos, evidenciando una capacidad creativa y colectiva de relatar lo local por medio de la capacidad de jugar con el espacio y la temporalidad haciendo uso de acontecimientos, lugares, actividades y personajes de manera dinámica y cambiante. Lo anterior, permite interpretar que los niños y niñas son capaces de ir configurando sus propios sentidos y significados sobre el pasado de Lo Hermida por medio de la articulación de sus particulares vivencias y otras fuentes de información como los medios de comunicación a los que están expuestos. Los niños y niñas, en este sentido, ofrecen la particularidad de situar sus marcos colectivos dentro de lo local. Específicamente en marcos espaciales como su pasaje, su casa, su escuela, su plaza o parque, y en algunos casos, la sede social. Esto posibilita que niños y niñas estén al tanto de lo que ocurre dentro de estos márgenes por lo que se vuelven en una suerte de visibilizadores de lo local. No solo lo hacen aparecer como lugar en donde transcurren sus historias, sino que presentan elementos y características densas del territorio como conflictos, personajes y elementos ahí presentes, a los cuales les otorgan un sentido.

Los niños y niñas entonces, logran caracterizar ciertos espacios, ciertas relaciones, ciertos personajes y ciertas situaciones de lo local con formas muy concretas. Al mismo tiempo que articulan una posición y un uso ético de esas caracterizaciones, por cuanto reflexionan los espacios y los personajes que articulan dentro de un relato cuya temática por lo general aborda problemáticas sociales de Lo Hermida. En este sentido, respeto a este uso ético asumen posiciones y definiciones respecto del camino valórico y conductual que deberían tomar las personas que 
habitan esos lugares de conflictos, así por ejemplo en el muro de Donald Trump no tienen problemas en tirarle botellas, golpearlo, etc. Siguiendo con este ejemplo también plantean que hay que recordar dónde y cómo murió asesinado un hombre para que nunca más pase o que si, por ejemplo, el muro no es compartido entre los vecinos este se perderá para todos, entre otras narraciones.

Los niños y niñas centran entonces sus historias entre ámbitos cotidianos como ir desde la escuela a la plaza, desde la plaza a su casa, desde su casa a la esquina, etc., o dentro de ellos (dentro de su casa, dentro de la sede, dentro del restaurant, etc.). Lo interesante es que si bien enmarcan sus relatos desde allí abren sus constelaciones de sentidos a otros marcos que parecen exteriores como los medios de comunicación, de los cuales toman conceptos e imágenes desde donde reinterpretan y redibujan sus ámbitos cotidianos invocando situaciones, personajes o lugares externos como el caso del muro de Donald Trump tantas veces ya comentado. En este sentido, el habitar Lo Hermida siendo niño o niña tiene la singularidad de estar situado en marcos sociales que la propia población posibilita: restaurantes, plazas, junta de vecinos, el pasaje, etc., que permiten a los niños y niñas habitar una infancia que trasciende los marcos en los que es situada tradicionalmente. Ya no es solo la escuela y la casa (Chávez, Vergara \& Vergara, 2010) los lugares donde el niño y la niña inscriben su habitar, sino más bien tanto esos lugares como lo que se presentan en la calle se vuelven lugares de posible tránsito para ellos y ellas en cuanto niños y niñas.

De esta manera uno podría interpretar que los niños y las niñas de Lo Hermida gestionan una amplia variedad de experiencias y sentidos que les permiten subsidiar sus construcciones sobre el pasado, exista o no exista una permanente transmisión del mundo adulto sobre el pasado de Lo Hermida. En este sentido, por ejemplo, la estatua del puño en rojo que se ubica en el complejo 
Manuel Gutiérrez quizás no ha sido explicada ni relatada por el mundo adulto hacia los niños y niñas, no obstante, los niños y niñas de Lo Hermida son capaces de identificarla como marca y de construirle un pasado con una finalidad específica para el presente de ellos y ellas. Habitar Lo Hermida entonces siendo niño y niña posibilita una serie de experiencias y vivencias tanto en lo doméstico como en lo público que facilitan la actoría y la agencia de estos sujetos frente a los sentidos y significados que se están produciendo tanto dentro del territorio como fuera de este, indistintamente si estos son producidos para la infancia o para el mundo adulto, los niños y niñas se las apropian igual.

La memoria entonces, se vuelve una herramienta para re-visitar estos lugares comunes y ampliar narrativamente las posibilidades de sentido de ciertos presentes dejando entrever una mirada de futuro sobre ellos que permitan, como se ha venido diciendo, volverlos habitables $\mathrm{y}$ transitables para el uso común. Por lo tanto, conocer los relatos del pasado que elaboran los niños y niñas sobre Lo Hermida, abre un campo de marcas y huellas vinculadas al territorio que les son significativas como niños y niñas miembros de una comunidad. Los niños y niñas dan entonces la posibilidad de que pudiera aparecer lo que quizás estaba escondido o sencillamente fuera de vista, con la particularidad de poseer una densidad en relación a lo local, producto de que sus memorias aún se constituyen básicamente en torno a este nivel.

En el caso aquí trabajado se podría suponer entonces que los niños y niñas utilizan por ejemplo la fantasía y la ficción como se ha venido exponiendo, con la finalidad de expandir los marcos dentro de los que se enmarcan y acceder temporalmente a eventos pasados cercanos y lejanos con al finalidad de dinamizar su cotidiano, tanto en el espacio público como en el ámbito doméstico, utilizando la fantasía como exageración y ruptura del cotidiano en tanto forma narrativa de expandir el relato sobre el pasado. Halbwachs hablaba de la ensoñación como mecanismo que 
posibilita la reconstrucción del pasado mediante la imaginación y la articulación de imágenes asociadas al placer y al amor, desplazando a un segundo plano lo penoso y lo triste de ciertas experiencias. De alguna manera la ensoñación promueve una memoria contemplativa desde la cual los sujetos logran "salir de la sociedad" (2004). Lo anterior, dirá el autor, con la intención de construir pasados con otras miradas que conocemos.

Lo local entonces se vuelve un nivel fundamental para los niños y las niñas al momento de entender su presente. Es en este nivel en donde el espacio se vuelve territorio, por cuanto estos sujetos conviven y transitan en la calle, el pasaje, la plaza y la sede vecinal, o sea, en el espacio público que Lo Hermida les presenta. Es en este espacio donde estos sujetos habitan rincones y lugares consolidados por la propia historia de la población, con marcas y cargas culturales importantes de períodos de resistencia, como las estatuas en las plazas o las sedes vecinales en donde participan activamente organizaciones sociales que a la par del pasado de la población funcionan autogestivamente como lo hacían en las tomas de terreno originarias y en las resistencias organizadas a la dictadura. Los niños y niñas juegan y crean alrededor de estos elementos y se van configurando como sujetos en relación a estos. Los interpretan y resignifican, y como se ha presentado, posicionan conflictos comunes de la población en ellos y asumen posiciones frente a estos. En este sentido, ser niño y niña en Lo Hermida permite re-situar al presente como temporalidad central puesto que la mayoría de sus narraciones hablan e invocan al pasado concretamente desde ahí. Se podría leer entonces que los niños y niñas buscan respuestas a "grietas" o "accidentes" que perciben en su cotidianidad dentro de la población, buscan respuestas a conflictos entre los vecinos, entre pares, a marcas que no entienden del territorio o situaciones que no entienden como la plaza en la que juegan que está llena de borrachos. En este sentido entonces, estos sujetos son actores sociales activos y capaces de agenciar el presente y con ello 
construir sus propios pasados respecto a este. Lo anterior, cobra relevancia en relación, por una parte, a los discursos del miedo llevados a cabo por el modelo neoliberal (Calveiro, 2015) en donde el espacio público pasa a ser un lugar peligroso, y por otra, al lugar temporal hegemónico en donde se sitúa la infancia, vale decir, orientada hacia el futuro.

Los niños y niñas se vuelven una bisagra entre las urgencias del presente y las constelaciones de sentido que habitan en la población, situadas en marcas, lugares, personajes e historias, al mismo tiempo, que hacen uso de los medios de comunicación para auxiliar los sentidos y significados que con sus experiencias no alcanzan a proporcionar a lo que viven. Los niños y niñas de Lo Hermida vivencian el presente y utilizan conceptos e imágenes propios de la historia de lucha de la población, así como también reproducen elementos hegemónicos como ciertas valoraciones y personajes más vinculados a los discursos de emprendimiento propios del neoliberalismo.

Finalmente entonces, atender a la construcción de memorias de Lo Hermida de los niños y niñas de la población, permite comprender los movimientos de los niños y niñas en relación a las urgencias de su presente en el territorio y su capacidad de agenciamiento respecto de la búsqueda de sentido frente a estas urgencias, por medio de la articulación de relatos sobre el pasado en donde arman y desarman las constelaciones de sentidos que buscan hegemonizarse en lo local, así como también las cargas culturales presentes en su territorio (marcas, huellas, prácticas, lugares, etc). Los niños y niñas de Lo Hermida atienden concretamente a su presente y transitan diversas posibilidades de pasados por medio de la fantasía y la ficción para proporcionarle un sentido a su actualidad, pero un sentido en términos colectivos, de unión, de conjunto, en donde quizás como sostenía Del Pino (2013), se busca construir un presente de buena convivencia en un lugar donde la violencia y la resistencia han marcado la historia de la población. 


\section{Referencias}

Álvarez, C. y Hedrera, L. (2015). Los niños también recuerdan: memoria, infancia y participación en Memorial de Paine, un lugar para la memoria. Facultad de ciencias sociales. Departamento de psicología. Escuela de psicología.

Aninat, M. (2016). ¿Qué es lo que se dice sobre mi territorio?: Un análisis de la construcción de imágenes simbólicas en la población Lo Hermida. Facultad de arquitectura, diseño y estudios urbanos. Instituto de estudios urbanos y territoriales. Pontifica Universidad Católica de Chile.

Canales, M. (2006). Metodologías de la investigación social: introducción a los oficios. Santiago: LOM ediciones.

Calveiro, P. (2006). Los usos políticos de la memoria. En Sujetos sociales y nuevas formas de protesta en la historia reciente de América Latina (pp. 358-383). Buenos Aires: CLACSO.

Calveiro, P. (2015). Políticas de miedo y resistencias locales. Athenea Digital, 15(4), 35-59.

Capella, C. (2011). Una propuesta para el estudio de la identidad con aportes del análisis narrativo. Revista Psicoperspectivas. 12(2), 117-128.

Chacón, N. (2017). Construcción de memorias sobre el conflicto armado de el Salvador en jóvenes de una comunidad desplazada (Tesis de magíster). Universidad de Chile.

Chávez, P., Vergara, A. \& Vergara, E. (2010). Televidencia y vida cotidiana de la infancia. Un estudio de casos con niños y niñas de Santiago. Polis. 9(26), 371-396.

Del Pino, P. \& Yezer, C.(Eds)(2013) Las formas del recuerdo. Etnografía de la violencia política en el Perú. Perú: IFEA.

Gianini, H. (2004). La "reflexión" cotidiana. Hacia una arqueología de la experiencia. Santiago: Editorial Universitaria. 
Halbawchs, M. (2004). Los marcos sociales de la memoria. Barcelona: Antropos Editorial.

Raposo, G. (2013). La memoria emplazada: proceso de memorialización y lugaridad en postdictadura. Revista de Geografia Espacios. 3(6): 63-97. Recuperado en https://www.google.com/search?client=ubuntu\&channel=fs\&q=raposo+2012\&ie=utf$8 \&$ oe $=$ utf- 8

Reyes, M., Jeanneret, F. \& Cruz, M. (2016). Memorias Locales y Transmisión Intergeneracional: estudio de caso de un "barrio crítico" en Santiago de Chile. Facultad de Ciencias Sociales, Departamento de Psicología, Departamento de Psicología. Proyecto FONDECYT N ${ }^{\circ}$ 1161026 "Memorias locales y transmisión intergeneracional: estudio de caso de un "barrio crítico" en Santiago de Chile

Recepción: 17 de mayo 2019

Última Revisión: 22 de julio 2019

Aceptación Final: 20 de noviembre 2019 